\title{
O TRAUMA EM TEMPOS DE VÍTIMAS
}

\author{
Fernanda Canavêz
}

Departamento de Psicologia, Programa de Pós-Graduação em

Psicologia da UFRRJ, Seropédica, RJ, Brasil.

Psicanalista, doutora em Teoria

Psicanalítica pela UFRJ, professora do Departamento de Psicologia e do Programa de Pós-Graduação em Psicologia da UFRRJ, membro do grupo de pesquisa Trauma e Catástrofe do Instituto de Educação (Depsi).
RESUMO: Investiga-se o trauma a partir da figura da vítima, uma das marcas da cultura atual. O objetivo é examinar a mudança no tratamento dispensado aos sujeitos tidos como traumatizados na passagem da modernidade freudiana para a contemporaneidade a partir de narrativas que versam, nos dois momentos, sobre experiências consideradas traumáticas. Conclui-se que há uma sensível diferença entre a noção freudiana de trauma, que remete ao excesso, ao inesperado, e aquela de traumatismo, um evento socialmente legitimado como produtor de vítimas. Ainda, sustenta-se a atualidade da clínica psicanalítica na sua potência para ultrapassar a identidade vitimizada e valorar os destinos sempre singulares do trauma.

Palavras-chave: Trauma, traumatismo, vítima, contemporaneidade.

ABSTRACT: Trauma in the time of victims. This paper investigates trauma from the figure of the victim, one of the hallmarks of current culture. The aim is to examine the change of treatments offered to subjects who are considered traumatized in the passage from Freudian modernity to contemporary through narratives that deal, on both occasions, with experiences taken as traumatic. What follows is an appreciable difference between the Freudian notion of trauma, which refers to the excess and the unexpected, as well as the traumatism, an event socially legitimized as a producer of victims. In addition, it sustains the actuality of the psychoanalytic clinic as a power that reveals the overcome of the victimized identity to appraise the always unique destinations of trauma.

Keywords: Trauma, traumatism, victim, contemporary.

DOI - http://dx.doi.org/10.1590/S1516-14982015000100004

\footnotetext{
*Versão ampliada do trabalho apresentado no VI Congresso Internacional de Psicopatologia Fundamental e XII Congresso Brasileiro de Psicopatologia Fundamental, Belo Horizonte, 4-7 de setembro de 2014 (CANAVÊZ \& HERZOG, 2014).
} 


\section{DO TRAUMA À VÍTIMA}

O tema do trauma é objeto de pesquisa nas mais diversas áreas de produção do conhecimento, dentre as quais as ciências humanas e sociais. É possível asseverar, a este propósito, que a própria psicanálise surge do estudo do trauma, uma vez que a pré-história da clínica aventada por Freud foi inteiramente dedicada à hipótese da etiologia traumática para a leitura dos sintomas histéricos que desafiavam a medicina à época. Trata-se, portanto, de um assunto que remete aos primórdios da clínica psicanalítica, mas persiste norteando inúmeros trabalhos do movimento psicanalítico desde Freud aos dias atuais, o que se expressa tanto pela vasta bibliografia a que se tem acesso quanto pelos vários fóruns de debate realizados nos últimos anos.

Esse panorama fala a favor da pertinência da investigação do tema, embora imprima a marca de um verdadeiro desafio a toda e qualquer pesquisa que se proponha a abordá-lo, qual seja, o de revisitar a produção anteriormente existente e, ao mesmo tempo, constituir uma contribuição fértil de fato face às particularidades de nossa época, aos traumas do nosso tempo. O grupo de pesquisa Trauma e catástrofe ${ }^{1}$ vem se dedicando ao estudo da articulação entre os dois conceitos na contemporaneidade e seus mais variados fenômenos, de modo que é na esteira dessa proposta que o presente artigo se insere, privilegiando a figura da vítima para analisar o trauma na atualidade, na medida em que aquela se revela absolutamente contemporânea.

Isso porque os discursos, sentidos e práticas que giram em torno do sujeito que passa por uma experiência entendida como traumática parecem estar em franca transformação nas últimas décadas, fomentando a constatação de uma verdadeira mudança na cartografia do mal-estar que, segundo Birman (2012), já se anunciava desde as décadas de 1970 e 1980, muito embora tenha se tornado mais evidente a partir dos anos 1990. A emergência da condição de vítima como personagem principal de narrativas que tomam o caráter traumático por predicado é um importante exemplo das metamorfoses sofridas pelo sujeito na atualidade.

A hipótese do destaque conferido à vítima, sobretudo nas últimas três décadas, norteia o livro dos franceses Fassin e Rechtman intitulado O império do traumatismo: investigação sobre a condição da vítima, trabalho que parte da afirmação de que o traumatismo tornou-se a chave para a interpretação do mundo contemporâneo, no qual se observa um encontro entre a produção social do trauma e o reconhecimento moral das vítimas.

\footnotetext{
${ }^{1}$ Grupo de pesquisa coordenado por Joel Birman e Christian Hoffmann em uma cooperação acadêmica internacional e interdisciplinar entre pesquisadores da UFRJ e da Université Paris-Diderot.
} 
Segundo os autores, assistir-se-ia nos dias atuais a uma reconfiguração contundente do que chamam de economia moral, responsável por regular o laço social, em que o traumatismo ter-se-ia tornado uma espécie de "nova linguagem do acontecimento" (FASSIN \& RECHTMAN, 2011, p.18, tradução nossa) capaz de transformar a maneira como os sujeitos se relacionam, pensam e constroem a história. Em última instância, caso se parta da premissa da inexistência de um fundamento universal e a-histórico do sujeito, cabe então indagar o que diferencia o modo de subjetivação característico da modernidade — em cujo seio a psicanálise surgiu — das versões encontradas na cultura atual. Segundo o livro em questão, são modos de subjetivação perpassados pela realidade do que se convencionou chamar de traumatismo.

O presente artigo objetiva extrair as consequências, no âmbito da clínica psicanalítica, da formulação do traumatismo como orientador da linguagem contemporânea do acontecimento, em que pese a atual valorização das narrativas que versam sobre as vítimas. Para tal, busca-se investigar continuidades e descontinuidades dessa leitura em relação ao discurso inaugural da psicanálise, calcado na clínica das histerias, assim como a operacionalidade da clínica psicanalítica em se tratando do que doravante é proposto na contemporaneidade, aqui privilegiada nos termos dos tempos das vítimas. Para a consecução desse objetivo serão analisadas, a partir de uma revisão bibliográfica, narrativas sobre os sujeitos entendidos como traumatizados nos dois momentos.

\section{O TRAUMA SOB SUSPEITA}

No âmbito da psicanálise o quadro enunciado como de transformações pelos franceses supracitados traz pelo menos uma grande indagação: em que medida a proposição do traumatismo como nova linguagem do acontecimento estaria distante do discurso inaugural da psicanálise, tendo em vista que Freud reconhecera na etiologia dos sintomas neuróticos justamente o caráter traumático? Para retomar de forma resumida e esquemática o pensamento freudiano acerca do tema ${ }^{2}$ cabe lembrar, em primeiro lugar, que a afecção neurótica foi referida a uma experiência factual de sedução que, pelo caráter traumático, deixaria uma marca passível de ser reativada após um período de latência, concorrendo para a formação sintomática conforme teorizado desde as chamadas publicações pré-psicanalíticas (FREUD, 1896/1976).

Já no quadro do segundo dualismo pulsional, após o abandono da teoria da sedução (idem, 1897/1977), o trauma figura como marca do psiquismo no que

\footnotetext{
${ }^{2}$ Uma vez que o trauma na obra freudiana não constitui objeto central do presente artigo, o leitor encontrará uma discussão pormenorizada e preliminar a respeito do tema em Canavêz (2012).
} 
este revela de excesso pulsional e, como tal, traumático para o sujeito (idem, 1920/1976). Também aqui se apresenta como paradigma do trauma uma situação de intensidade extrema que coloca em xeque os mecanismos defensivos comumente utilizados pelo aparelho psíquico. É o que faz com que Kehl (2000) aproxime o termo trauma da ideia de catástrofe, pois o vocábulo busca nomear o que resta de "certos acontecimentos da vida, sobre os quais não conseguimos nos pronunciar. Podemos chamá-lo, como Freud, de trauma” (p.137).

Desta feita, a breve retomada do pensamento de Freud permite afirmar que, se for possível depreender um modo de subjetivação mais predominante em sua obra, certamente se trata daquele traumatizado. O sujeito freudiano é, por excelência, traumatizado. Então o que de fato mudou para a afirmação atual do traumatismo como paradigma do acontecimento ou do traumático como modo de fazer história e subjetivação?

Se, por um lado, parece difícil vislumbrar uma diferença mais marcante entre as duas épocas - a modernidade freudiana e a contemporaneidade — referente à figura do trauma, por outro, com respeito à leitura que se faz da figura da vítima, na cultura atual, talvez não se possa dizer o mesmo. Desse modo, tal figura auxilia a ilustrar uma contundente descontinuidade entre o sujeito do qual Freud falava e aquele com o qual a psicanálise lida atualmente. Isso porque haveria a passagem de um momento no qual os sujeitos que se enunciavam como traumatizados eram alvo de suspeição, sob a alegação de simularem o mal-estar que os acometia, para outro paradigma em que o traumatismo revela-se premissa exclusiva para conferir a estes a característica de vítima.

Em outros termos: ter-se-ia operado o deslocamento de uma cultura que suspeita da autenticidade do sofrimento de sujeitos que vivenciaram experiências extremas e disruptivas para outra em que o fato em si, legitimado como traumático, é suficiente para conferir autenticidade à narrativa dos envolvidos. Para exemplificar essa descontinuidade é possível revisitar o tratamento dispensado aos chamados neuróticos de guerra à época da Primeira Guerra Mundial, sujeitos passíveis de serem tomados pela clínica — fosse ela médica ou psicanalítica — como traumatizados.

Recaíam sobre estes acusações de que estariam se furtando ao compromisso com sua pátria de acordo com duas possibilidades diagnósticas principais: ou evidenciavam certa relutância em abandonar sintomas simulados para escapar do front de batalha, ou eram portadores de uma fragilidade psíquica prévia deflagrada pelo gatilho dos horrores da guerra. Coube ao discurso psicanalítico, naquele momento, apontar para a verdade inconsciente que era escamoteada pela exigência de determinar se se tratava ou não de simuladores em busca de benefícios. 
Para ilustrar o tratamento dispensado aos traumatizados, até então corrente na medicina moderna, é possível evocar o episódio em que Freud fez um pronunciamento a respeito do assunto da simulação de sintomas. O que estava em jogo era uma espécie de inquérito, tendo por alvo o psiquiatra austríaco Wagner-Jauregg, que acusava neuróticos de guerra de simulação deliberada de sua enfermidade, tratando-os por meio de eletroconvulsoterapia (ROUDINESCO \& PLON, 1998).

Freud foi inserido no debate na condição de perito e fez o seguinte pronunciamento, citado por Eissler (1992): “todas as neuroses são de simulação, eles simulam sem saber, e esta é a sua doença” (p.290, tradução nossa). Criticou então não apenas o uso demasiado do eletrochoque, mas também a acusação de que os pacientes estariam deliberadamente fingindo ter algum acometimento. Além disso, a afirmação freudiana distancia-se da teoria da sedução, pois lembra que a realidade psíquica — vale enfatizar: realidade traumática — é decisiva, como Freud (1916-17/1976) postulara, de forma que a determinação psíquica é incluída nas forças que concorrem para a produção do trauma juntamente com o fato em si.

Se as neuroses de guerra estavam sob a mira da suspeição da medicina e demais setores da sociedade, coube à psicanálise valorar os modos pelos quais o inconsciente se manifesta e, pode-se afirmar, por meio dos quais o sujeito confere um destino ao trauma que o assola. Além disso, o posicionamento de Freud subverte o tratamento moral reservado ao sujeito que sofre, como se à clínica coubesse exclusivamente a tarefa de advogar a favor ou contra a pretensa autenticidade de suas formações sintomáticas. Com efeito, Freud desloca o julgamento moral para uma clínica orientada pela posição do sujeito diante de seu trauma particular — para além, inclusive, do acontecimento em si.

\section{DO TRAUMA AO TRAUMATISMO}

Uma vez que o termo trauma apresenta inegável polissemia no movimento psicanalítico (RUDGE, 2006), cumpre reiterar que este é compreendido neste artigo em uma das acepções específicas em que é tomado nesse campo, qual seja, como marca do excesso, do que extrapola à possibilidade de representar e, como tal, de fazer qualquer antecipação. Nos termos do segundo dualismo pulsional freudiano, refere-se à impossibilidade de ligação da energia pulsional por meio de uma cadeia de representações. Essa observação é importante para avançar na discussão doravante proposta sobre trauma e vitimização na contemporaneidade, posto que ressalta o aspecto relacional em jogo na atribuição do caráter excessivo ao trauma. Desse modo, o excesso pode ser depreendido a partir de duas condições fundamentais e concorrentes: por um lado, há uma intensidade extrema que desorganiza os mecanismos defensivos dos quais o 
aparelho psíquico se utiliza; por outro, a inexistência do preparo para lidar com aquela. Não há, portanto, a preponderância de um desses fatores na atribuição do caráter traumático à experiência.

Assim, a etiologia traumática aglutina diferentes vertentes que contribuem para a precipitação do trauma, de maneira que o acontecimento, o sujeito e o ambiente circundante não são tomados de modo isolado, mas sempre em relação. Trata-se de um registro absolutamente singular, pois dependente de uma série de fatores que se entrelaçam para a produção de algo cuja leitura só é possível no caso a caso, ainda que o sujeito tenha passado por uma situação entendida como disruptiva e excessiva. Em outros termos: a clínica psicanalítica permite inferir que o fato de ter passado por uma situação extrema não é causa lógica e direta da produção de um trauma. De maneira análoga, o trauma pode se impor sem a premissa do que se pactua coletivamente como excessivo.

Essa acepção de trauma não coincide, em absoluto, com aquela de traumatismo. Este é um fato incontestável, um acontecimento caracterizado, em um dado momento, por seu potencial de subverter uma determinada ordem estabelecida. Um acontecimento, portanto, socialmente construído - e autorizado - como traumático por subverter uma ordem igualmente construída. Sendo assim, diferentes situações podem ser designadas sob a égide do traumatismo, variando conforme as forças atuantes para a produção de determinada cultura. É possível citar os acidentes ferroviários e a Primeira Guerra Mundial à época de Freud, os ataques nucleares a Hiroshima e Nagasaki por ocasião da Segunda Grande Guerra e, mais recentemente, para evocar situações ainda mais próximas de nossa realidade, episódios como o acidente com o voo 447 da Air France, em maio de 2009, e o incêndio na boate Kiss, em Santa Maria (RS), em janeiro de 2013.

Tais acontecimentos expressam a distância entre traumatismo e trauma na medida em que o primeiro termo se mostra uma construção social, pressupondo uma espécie de comoção coletiva. Antes de prosseguir é preciso fazer uma ressalva: não se trata de circunscrever o trauma à dinâmica individual, enquanto o traumatismo estaria inserido no âmbito social, coletivo. Acompanhando Freud (1921/1976), entende-se que a psicologia individual é desde sempre social, o que, aliás, atesta a pertinência de lançar luz sobre os fenômenos culturais quando a discussão sobre os modos de subjetivação está em pauta. De acordo com Peixoto Junior (1999), a leitura freudiana permite substituir a oposição entre individual e social por aquela entre “atos psíquicos narcísicos e atos psíquicos sociais” (p.122). Marcada que é por um jogo de forças — narcísicas e sociais - a subjetivação se faz em um permanente processo de invenção de si, ora aproximando-se dos discursos que parecem hegemônicos, ora a estes resistindo para preservar o que apresenta de mais singular. 
Assim, concebendo o traumatismo como uma construção social procura-se enaltecer a emergência de uma nova ordem moral — portanto, hegemônica segundo a qual determinadas situações são privilegiadas na busca por reparação, comoção e legitimação social. Cumpre destacar que não se está necessariamente na dimensão do inesperado, pelo menos não do que escapa a toda e qualquer possibilidade de antecipação. A esse respeito, é oportuno lembrar o caso dos deslizamentos de encostas, ocorrido na passagem de 2009 para 2010 na região fluminense da Costa Verde, que se reedita a cada ano no período das chuvas de verão.

Nessa situação específica não se trata de uma catástrofe exclusivamente natural, mas também de uma tragédia anunciada que faz convergirem inúmeras forças, dentre as quais o descaso por parte do poder público frente às desigualdades sociais, a corrupção, um processo de urbanização desordenado e assim sucessivamente. Extrapola-se o registro do inesperado, sempre atrelado à noção psicanalítica de trauma, para exaltar certo uso social do traumatismo.

Então, se antes os discursos médico e psicanalítico eram convocados a opinar na querela do julgamento moral dispensado aos traumatizados, a cultura contemporânea confere ao traumatismo o estatuto de verdadeiro recurso de legitimação de uma determinada verdade sobre o sujeito — nesse caso, o sujeito vitimizado. Estão estabelecidos os parâmetros para a emergência da condição social da vítima.

\section{EM TEMPOS DE VÍTIMAS}

Um passo decisivo nas transformações que levaram à condição social da vítima tal qual se apresenta na contemporaneidade foi a publicação e a apropriação pela clínica médica da terceira versão do Manual diagnóstico e estatístico dos transtornos mentais, o DSM III, nos anos 1980, que apresenta a categoria diagnóstica transtorno de estresse pós-traumático (APA, 1980). Os sintomas relacionados ao transtorno são interpretados como uma reação "normal” — isto é, estatisticamente esperada - face ao acontecimento chamado fator estressor traumático, que deixa de ser indício de uma fragilidade prévia apenas deflagrada por uma vivência extrema.

Fassin e Rechtman (2011) destacam que "Não se emite mais dúvida sobre a sinceridade do traumatizado: ele é a priori confiável. Não se interroga mais sobre os benefícios secundários: o diagnóstico habilita uma justa reparação” (p.120, tradução nossa). Diagnóstico este calcado principalmente na intensidade da experiência, isto é, no traumatismo, retirando da equação etiológica o peso outrora destinado ao sujeito, nem que este fosse classificado de frágil e de saída impotente para lidar com os contratempos da vida, conforme queriam certas acusações endereçadas aos neuróticos de guerra. 
Tal contexto serve de pano de fundo para Eliacheff e Larivière (2007) afirmarem que se verifica, no discurso do DSM III, a eliminação da subjetividade, marcando uma ruptura radical na história da psiquiatria. Na perspectiva desses autores, o Transtorno de estresse pós-traumático (TEPT) apagaria os traços do sujeito em um esforço para fazê-lo caber no predicado de vítima, uma figura “inocentada” pela psiquiatria de uma história prévia para lhe ser outorgado o direito à reparação. O trabalho em questão apresenta um cenário a partir do qual se pode depreender certo esforço do discurso psiquiátrico para livrar a vítima de quaisquer objeções de cunho moral, momento circunscrito ao retorno dos veteranos da Guerra do Vietnã, na década de 1970. Longe de serem aclamados como heróis pela sociedade estadunidense, muitos destes foram considerados antissociais e agressivos, comportamentos atrelados à então chamada Síndrome Pós-Vietnã, vista, nesse sentido, como uma espécie de precursora do TRPT.

Sobre esse aspecto, vale dar voz aos autores:

“A nova formulação (estado de estresse pós-traumático), sob uma aparência anódina (a existência de um patente evento estressor que provocaria sintomas evidentes de desamparo na maior parte dos indivíduos), elimina toda subjetividade: se a vítima presumida viveu a experiência e apresenta os sinais clínicos de TEPT, então se trata de uma autêntica vítima." (ELIACHEFF \& LARIVIÈRE, 2007, p.40, tradução nossa)

Por conseguinte, é como se os sujeitos fossem esvaziados em suas diferentes histórias, narrativas e modos de lidar com o trauma, e adquirissem, em troca, a identidade de vítima, em que pese o fato de sermos todos vítimas em potencial, passíveis que somos de desenvolver os mesmos sintomas diante do evento estressor.

A contemporaneidade seria, assim, uma cultura da vitimização no que evidencia de possibilidade de generalização da condição da vítima. Os exemplos mais recentes — citados na seção anterior para ilustrar eventos cujo potencial traumático é irrefutável — também são paradigmáticos nesse quesito: tanto o acidente do voo da Air France quanto o incêndio na boate Kiss rapidamente deram ensejo à reunião de familiares dos falecidos e, no segundo caso, também de sobreviventes, em associações ${ }^{3}$.

Com isso, é possível afirmar que o discurso psi perdeu ênfase no mandato de legitimação que anteriormente lhe era atribuído: de saída a vítima é reconhecida e o traumatismo é reinvindicado (FASSIN \& RECHTMAN, 2011), descortinando

\footnotetext{
${ }^{3}$ Para mais detalhes consultar os sites da Associação dos familiares das vítimas do voo 447 e da Associação dos familiares de vítimas e sobreviventes da tragédia de Santa Maria: http:// www.afvv447.org/ e http://avtsm.org/a-avtsm/.
} 
todo um campo de militância em defesa dos direitos das vítimas e, sobretudo, da possibilidade de receber alguma reparação pelo dano sofrido. Aliada à emergência da figura da vítima, reconhece-se, portanto, mais uma transformação na passagem da modernidade para a contemporaneidade, qual seja, a convocação com fins de legitimação outrora feita ao discurso psi não parece ser mais tão necessária em um quadro em que o acontecimento, o fato em si, antecipa a legitimação da experiência dita traumática.

Delineia-se agora outra cena, apresentada em O império do traumatismo, sensivelmente distinta do pronunciamento de Freud evocado antes. Esta se deu por ocasião da explosão ocorrida no complexo industrial AZF [AZote Fertilisants], na região francesa de Toulouse, que deixou dezenas de mortos e inúmeros feridos em 2001, quando a representante de um coletivo de associações se pronunciou:

“Nós demandamos reparação através do dinheiro, através do palpável. Para os que não conseguem dar nomes ao que é impalpável, é importante lhes dar um nome e reconhecê-los como vítimas, quaisquer que sejam estas. Quero dizer com isto que a palavra vítima tem um sentido para estes.” (p.218, tradução nossa)

Independente dos destinos singulares que constituem desdobramentos para cada sujeito impõe-se-lhe a condição de vítima, apontando para o uso social do traumatismo, um recurso legitimado coletivamente. Convém esclarecer que seria demasiado ingênuo empreender um esforço seja de crítica, seja de positivação da demanda por reparação. A caça às bruxas da simulação em busca de supostos benefícios decorrentes de situações tão extremas, citadas há pouco, decerto ficou no século XIX, de modo que, enquanto contemporâneos, facilmente somos impelidos a um discurso de responsabilidade coletiva e empatia que tome por objeto a figura da vítima, o que faz com que alguns indiquem a delicadeza da questão na atualidade (KOLTAI, 2002). Essa delicadeza diz respeito ao ponto de chegada das transformações na economia moral que retiraram os tidos como traumatizados dos recônditos da imoralidade para a legitimação social da figura da vítima.

Questionou-se acima se esse estado de coisas estaria de fato tão distante do discurso que inaugurou a psicanálise, marcado pela presença de um sujeito traumatizado. Aqui, mais uma vez a distinção entre trauma e traumatismo se impõe: a insistência do trauma se faz notar no que evidencia de excesso pulsional, mostrando uma continuidade com o discurso inaugural da psicanálise. Em contrapartida, o uso social do traumatismo confere destaque à figura da vítima, dando-lhe o estatuto de legitimidade que independe dos destinos que cria para lidar com seu trauma particular. 
Convém indicar em que medida as noções de traumatismo e de trauma podem ser tomadas em contraponto. Se o trauma é correlato da suspensão de determinada ordem, se possui o inegável caráter de exceção em relação ao que seria esperado, como equipará-lo ao traumatismo, tendo em vista que este se tornou uma chave de interpretação, linguagem do acontecimento, da qual se lança mão quando determinadas situações se impõem? A construção social do traumatismo aponta, ao contrário da experiência do trauma, para as tentativas de construção de parâmetros, formas de intervenção e discursos de prevenção. "O traumatismo (...) faz parte do senso comum; ele tem valor descritivo, mais ainda prescritivo; ele demanda ação (clinicamente, economicamente e simbolicamente) e reparação” (FASSIN \& RECHTMAN, 2011, p.229, tradução nossa).

Além disso, há uma inquestionável generalização e, por conseguinte, banalização do estatuto da vítima que serve de norteador para uma leitura no mínimo curiosa. Antes, o sujeito era acusado de uma pretensa fragilidade psíquica ou até mesmo de simulação do sofrimento em busca de benefícios, hipótese responsável por deslocar a importância do acontecimento excessivo para a culpabilização do traumatizado. O foco estava no sujeito, mas única e exclusivamente para lançar luz sobre determinado uso que este poderia fazer do traumatismo e não propriamente para positivar uma narrativa singular a respeito do ocorrido.

Na passagem para a contemporaneidade, ao contrário, o peso recai sobre o acontecimento, constando o sujeito como acessório ao qual é reservado, de saída, o estatuto de vítima. Mais uma vez, sua narrativa é inserida em um quadro maior de prescrições que parecem destinadas à corroboração de uma determinada linguagem do acontecimento, destacando-se dessa vez o uso que a própria cultura faz do traumatismo.

Nesse quadro de prescrições para o qual a psicanálise também é convocada, pelo menos uma grande questão se coloca: em que medida a legitimação social da vítima concorreria para conferir um lugar para este sujeito ou tornar-se-ia ela própria traumática, na tentativa de universalizar destinos sempre singulares de um trauma? Fassin e Rechtman (2011) fornecem estofo para a resposta a esta indagação:

“a produção social do trauma e o reconhecimento moral das vítimas tiveram um custo. Não somente todas e todos não tiveram acesso a esse status e aos benefícios eventuais que daí poderiam extrair, mas mesmo aquelas e aqueles que eram suscetíveis de se reclamar como tais perderam uma parte de sua história e muito de sua capacidade de contá-la." (p.IV, tradução nossa)

Na luta pela garantia do necessário reconhecimento social e da legitimação da condição de vítima, corre-se o risco de cristalizar uma identidade — viti- 
mizada, vale dizer — às expensas da invenção de si que pode ser suscitada pelo trauma. Invenção que se dá em um permanente jogo de forças do qual fazem parte a posição do sujeito face ao trauma, o traumatismo sinônimo da linguagem contemporânea do acontecimento e também a identidade de vítima que dela decorre, a relação construída com o analista que se propõe a escutar esse sujeito e assim por diante.

Segundo essa leitura, o discurso psicanalítico pode, exatamente à maneira do deslocamento operado por Freud do tratamento moral dispensado aos neuróticos de guerra, problematizar essa "nova” economia moral no que expressa de imposição de uma determinada identidade, a de vítima. Face ao traumatismo e seu correlato, a condição social da vítima, a psicanálise pode convidar a uma restituição do trauma - que não coincide com o traumatismo, não parece demasiado ressaltar — , no que expressa de convocação do sujeito a uma permanente construção de si minimamente desembaraçada das identidades que lhe são imputadas em um dado momento, em uma determinada cultura. Reside aí a afirmação da operacionalidade da clínica psicanalítica ainda hoje, que se apresenta tão ou mais necessária do que à época do traumatismo suscitado pela Primeira Guerra Mundial.

Recebido em 3/12/2014. Aprovado em 9/2/2015.

\section{REFERÊNCIAS}

AMERICAN PSYCHIATRIC ASSOCIATION (1980) Diagnostic and statistical manual of mental disorders (DSM-III). DC: APA.

BIRMAN, J. (2012) O sujeito na contemporaneidade. Rio de Janeiro: Civilização Brasileira.

CANAVÊZ, F. (2012) "Violência, trauma e resistência: sobre o múltiplo na psicanálise”. Tese de Doutorado, Programa de Pós-Graduação em Teoria Psicanalítica, Instituto de Psicologia, Universidade Federal do Rio de Janeiro.

\& HERZOG, R. (2014) Trauma e vitimização na contemporaneidade, trabalho apresentado no VI Congresso Internacional de Psicopatologia Fundamental e XII Congresso Brasileiro de Psicopatologia Fundamental, Belo Horizonte, 4-7 de setembro.

EISSLER, K. (1992) Freud sur le front des névroses de guerre. Paris: PUF.

ELIACHEFF, C. \& LARIVIÈRE, D. (2007) Le temps des victimes. Paris: Albin Michel.

FASSIN, D. \& RECHTMAN, R. (2011) L'empire du traumatisme: enquête sur la condition de victime. Paris: Flammarion. 
FREUD, S. Edição brasileira das obras psicológicas completas de Sigmund Freud. Rio de Janeiro: Imago.

(1897/1977) “Carta 69”, v.I, p.350-352.

(1896/1976) “A etiologia da histeria”, v.III, p.215-249.

(1916-17/1976) "Conferência XXIII — Os caminhos da formação dos sintomas”, v.XVI, p.419-440.

(1920/1976) “Além do princípio de prazer”, v.XVIII, p.13-85.

(1921/1976) “Psicologia de grupo e análise do ego”, v.XVIII, p.89-179.

KEHL, M.R. (2000) “O sexo, a morte, a mãe e o mal”, in NESTROVSKI,

A. \& SELIGMANN-SILVA, M. (Orgs.). Catástrofe e representação. São Paulo: Escuta.

KOLTAI, C. (2002) Uma questão tão delicada. Psicologia Clínica, 2(14). Rio de Janeiro: Companhia de Freud, p.35-42.

PEIXOTO JUNIOR, C.A. (1999) Metamorfoses entre o sexual e o social: uma leitura sobre a teoria psicanalítica da perversão. Rio de Janeiro: Civilização Brasileira. ROUDINESCO, E. \& PLON, M. (1998) Dicionário de psicanálise. Rio de Janeiro: Zahar.

RUDGE, A.M. (Org.) (2006) Traumas. São Paulo: Escuta.

Fernanda Canavêz

fernandacanavez@gmail.com 